\title{
LAS ESCUELAS DE PRIMERAS LETRAS EN LA CARTOGRAFÍA SOCIAL DE LA CAMPAÑA BONAERENSE EN LA PRIMERA MITAD DEL SIGLO XIX
}

\section{PRIMARY SCHOOLS IN THE SOCIAL CARTOGRAPHY OF BUENOS AIRES' COUNTRYSIDE IN THE FIRST HALF OF THE 19TH CENTURY}

Lucía Lionetti*

\begin{abstract}
Resumen: En el presente artículo se estudia la escolarización en la campaña bonaerense en la Argentina de la primera mitad del siglo XIX. En un contexto de inestabilidad política y diversificación social y económica, la escuela devino en un teatro social donde los vecinos notables de las comunidades, las autoridades locales civiles y religiosas así como las autoridades estatales, libraron disputas al tiempo que negociaron dando forma a un nuevo entramado de poder sobre el que se construyó la nueva gobernabilidad de la provincia.
\end{abstract}

Palabras clave: Campaña bonaerense. Escuelas. Vecinos. Autoridades. Comunidades

Abstract: This article studies schooling in Buenos Aires' countryside in Argentina between in the first half of the 19th century. In a context characterized by political instability and social and economic diversification, the school developed into a social theatre where the communities' notable "vecinos", the local civil and religious authorities and also state authorities challenged each other while at the same time they negotiated, thus generating a new structure of power on which the governability of the province was built.

Keywords: Buenos Aires’ countryside. School. Neighbors. Authorities. Communities

\section{Introducción}

En estos dos últimos años, en el marco de los festejos del Bicentenario, los historiadores latinoamericanos han promovido entusiastamente una serie de revisiones sobre aquel proceso que llevó a la independencia de las colonias españolas de su metrópoli y a la construcción de un nuevo orden político. Sin embargo, a pesar de la profusión de estudios que se han publicado analizando las perspectivas económicas, políticas, sociales y culturales de aquellos años, escasamente se han planteado trabajos que exploren la cuestión educativa de aquellos años. En el caso específico de la Argentina, existen muy pocos trabajos que se hayan ocupado de analizar la cuestión de la instrucción elemental en el contexto de la sociedad post independiente. En general, se ha focalizado el interés por analizar la problemática educativa a fines del siglo

\footnotetext{
*Docente e Investigadora del Instituto de Estudios Histórico-Sociales “Prof. Juan Carlos Grosso”/Facultad de Ciencias Humanas/Universidad Nacional del Centro. Argentina. E-mail: <lucialionetti@ciudad.com.ar>.; <lionettilucia@gmail.com>.

* Professor and researcher at the Institute of Historical-Social Studies "Prof. Juan Carlos Grosso"/ Human Sciences College/ National University of Central Buenos Ayres/Argentina. E-mail: <lionettilucia@gmail.com>.
} 
XIX cuando el Estado Nacional estuvo en condiciones de sancionar la Ley 1420 de educación, común, laica y obligatoria "para todos los niños y niñas de la república” (LIONETTI, 2007). Tal parece que el mito fundacional de esa escuela pública, consagrada por su voluntad universalizadora, opacó las experiencias alcanzadas por las primeras escuelas elementales.

En las primeras décadas del siglo XIX, las emergentes repúblicas nacionales latinoamericanas estuvieron concentradas en sus diversos procesos de emancipación e independencia, conformando sus imaginarios en torno al concepto de patria y ciudadano (Irurozqui-Peralta: 2003). La instrucción, estimada como instrumento de sociabilización de valores, tuvo una vital relevancia en la transformación de los siervos del despotismo ilustrado en ciudadanos libres e iguales, artífices del progreso de la comunidad soberana (Quijada: 1993-1994). En el caso argentino, a partir de la segunda mitad del siglo XIX, y tras el impacto de la generación romántica de $1837^{1}$ y la caída del gobierno rosista en Buenos Aires, se iniciaron significativas discusiones sobre el rol del estado en la formación de sus futuros ciudadanos. Así, se cuestionó el monopolio -que durante la etapa colonial- tuvo la Iglesia Católica en la educación y formación de la infancia, planteando -desde posturas proclives a un creciente laicismo- un nuevo modelo de escolarización que permitiría erradicar los lastres que, en términos de Sarmiento, se arrastraban de una barbarie

\footnotetext{
${ }^{1}$ Así se llamó al grupo de jóvenes intelectuales que, identificados con las ideas del romanticismo utópico de Saint Simon, actuó contra el mandato de Juan Manuel de Rosas quien gobernó la Provincia de Buenos Aires entre 1829 y 1852 con un interregno entre los años 1832 a 1835. Dentro de sus principales exponentes encontramos a Juan Bautista Alberdi, Domingo Faustino Sarmiento, Bartolomé Mitre y Esteban Echeverría.
}

que encontraba sus raíces en el pasado colonial (FERRO GABO, 2008).

En ese sentido, la campaña bonaerense permite dar cuenta de las primeras iniciativas alfabetizadoras hasta una creciente presencia de la administración estatal. Caracterizada por ser una sociedad de frontera, un mundo rural dinámico, abierto y móvil, donde el proceso de construcción del estado debió batallar con una sociedad heterogénea que tenía un entramado de relaciones sociales estrechas entre sí, pero de relaciones muy laxas con el poder estatal que pretendía institucionalizarse. Percibido por las elites ilustradas como un espacio que propició la acción de las políticas facciosas de caudillos como Rosas y el ingreso de los sectores subalternos a la vida política, se promovió a la escuela de primeras letras con el propósito que extendiera los beneficios de la civilización en ese mundo rústico y de costumbres bárbaras.

En el presente artículo se pretende analizar el despliegue de las políticas y acciones de particulares y de autoridades en favor de la radicación de las escuelas de enseñanza elemental en esa cartografía rural de la campaña bonaerense. A partir de la consulta de las fuentes cualitativas -como la prensa, registros oficiales, correspondencias y archivos municipales- a las que se ha podido acceder, se pretende mostrar de qué modo aquella voluntad alfabetizadora reposaba sobre la convicción de que para edificar una "república de gente decente” era preciso cambiar hábitos y comportamientos de la niñez pobre. Se partía, de este modo, de la premisa de que los habitantes del campo carecían de cultura, puesto que sus creencias, prácticas y formas de convivencia eran “primitivas” o incluso "salvajes”. Tal como se verá, en el marco de aquella concepción de llevar la civilización de la ciudad al campo, se prodigaron de modo compartido 
las iniciativas de autoridades y referentes de las comunidades. Una acción compartida que tuvo sus puntos de encuentro pero también de tensión a la hora de hacer efectivo el funcionamiento de esas escuelas elementales. Las distancias entre las expectativas y los límites que imponía aquella realidad social para hacer efectiva esa alfabetización fueron aspectos sobresalientes de esas experiencias de escolarización elemental.

\section{La vida económica y social de la campaña de Buenos Aires}

Cuando se habla de la campaña bonaerense nos referimos a aquel punto de referencia que fuera el puerto y la ciudad de Buenos Aires -convertida en capital de virreinato en 1776- y que desde fines del siglo XVIII comenzó un proceso que se extendería a lo largo de todo el siglo XIX marcado por el desarrollo económico y la diversificación social. A comienzos del siglo las guerras de independencia, tras la ruptura con la metrópoli, provocaron el dislocamiento del eje económico que unía el centro minero de la Villa de Potosí -actualmente territorio perteneciente a Bolivia- con el puerto de Buenos Aires (HALPERÍN DONGHI, 1972). La disgregación del circuito económico, por el cual la metrópoli extraía a través del comercio y de la renta impositiva la plata potosina, provocó cambios sustanciales en la región circundante al puerto de Buenos Aires. Tras algunos años de incertidumbre, la creciente demanda de productos pecuarios por parte de mercados europeos hizo posible que las remesas de plata fueran reemplazadas por cueros y derivados del ganado -tasajo, sebo, crines-.

La cercanía a la ciudad de Buenos Aires implicó la posibilidad de producir bienes como cereales u hortalizas para el abasto del mercado. El segundo grupo de poblados tuvo una producción mixta. Se encontraban establecimientos dedicados a la agricultura, pero ya aparece con mayor presencia el ganado. Éste sería aún más abundante hacia el tercer cinturón productivo.

Estas transformaciones complejizaron su escenario social con la presencia de actores claves, como los terratenientes, chacareros arrendatarios, ${ }^{2}$ gauchos que contribuyeron a la exitosa inserción de la región al mercado mundial. A su vez, la expansión agraria promovió la incorporación de tierras y el avance sobre una frontera de contactos intra e interétnicos e incluso intersociales (MANDRINI, 1992; MAYO, 2002; RATOORTELLI, 2008). En aquel mundo social parecía confrontar la “civilización” con el “salvajismo”, el territorio poblado con el “desierto”, sin embargo, el carácter móvil y abierto de ese mundo lo convirtió en un lugar de oportunidades económicas y de ascenso social que, en la mayor parte de los casos, no estaban destinados a perdurar. Esa frontera estuvo marcada por una larga historia de la llamada "conquista del desierto"; por el reparto de la tierra pública, por la expansión horizontal de las actividades económicas en nuevas tierras -la ganadería primero (ovina y vacuna, en ese orden), la agricultura después y por el progresivo asentamiento de inmigrantes en esas tierras -nacionales primero, extranjeros después- (PALACIO, 2004, p.42).

En aquel contexto, los pueblos que conforman la campaña de Buenos Aires -no más de una treintena pequeñas comunidadescontaban entre unos 500 y unos 3000

\footnotetext{
2 Se designaba “chacarero" al agricultor que era productor de una chacra -pequeñas parcelas dedicadas a la producción agrícola-. Eran en su mayoría de origen inmigrante y a lo largo del siglo $\mathrm{XX}-\mathrm{y}$ fundamentalmente con el peronismo- devino en un "pequeño propietario.
} 
pobladores. Para 1850, algunos de ellos, tenían 7000 u 8000 habitantes. El proceso de poblamiento se dio sobre espacios diferentes. La zona de antiguo poblamiento, conformada por los poblados apostados a los márgenes del Camino Real que comunicaba Buenos Aires con el Interior; y el nuevo sur, una amplia zona de frontera con sociedades indígenas sobre las márgenes septentrionales del río Salado. Las condiciones productivas de esta región estuvieron determinadas por una serie de variables (GARAVAGLIA, 1989). Un 40 \% del total de los habitantes de la región serían menores de 14 años (MORENO, 2000). Las altas tasas de mortandad infantil harían suponer que en un pueblo de 1000 habitantes apenas unos 100 estarían entre los 6 y los 12 años. Fueron recurrentes las migraciones de hombres adultos provenientes de la región interior del país, atraídos por la demanda estacional de mano de obra que se producía con la cosecha estival. Cuando fueron acompañados por sus familias se transformaron en pobladores permanentes.

\section{Las Escuelas de primeras letras: un enclave de la ciudad en la campaña}

Tal como se ha presentado, la campaña se presentaba como un lugar de oportunidades económicas y de ascenso social que, sin embargo, en la mayor parte de los casos no estaban destinados a perdurar. Sin embargo, la visión desde la ciudad de Buenos Aires reforzaba la imagen de un territorio sumido en la barbarie. Al peligro que entrañaban las excursiones de malones indígenas -los salvajes carentes de cultura- se sumaba ese mundo bárbaro de la rusticidad.

Sobre esa realidad, la ciudad de Buenos Aires pretendía llevar las luces de la instrucción. El gobierno de la revolución retomó aquel impulso educativo que ya se había hecho presente en tiempos de la Colonia. La prensa comprometida con el ideario revolucionario, divulgó los preceptos revolucionarios para impulsar desde sus páginas la idea de que era preciso difundir las luces de la instrucción con el objeto de formar a un ciudadano "virtuoso e ilustrado" sobre el que se cimentaría el nuevo orden independentista. Con esa convicción, en uno de esos medios, se sostenía que: “[...] El país se halla en una infancia general en todo sentido y en la necesidad de aspirar a todo tipo de gloria [...] en fin esforzarse por ser contado entre los pueblos cultos e ilustrados que honran tanto a la especie humana” (EL CENSOR, n. 80, 27/03/1817). ${ }^{3}$

Tal como se afirmaba con vehemencia, los pueblos embrutecidos y contagiados por la opresión y el error, no serían susceptibles de ninguna reforma pacífica mientras no se les cure. Por eso era "preciso dirigirse a la generación naciente; y tal es el objeto de la educación nacional”. Para conseguir ese propósito se opinaba "[...] que bastaban veinte años para regenerar [...] si se enseñase gratuitamente a todos los niños y jóvenes pobres lo que es útil y necesario a la sociedad, adaptándose a métodos de enseñanza fáciles y sencillos” (EL CENSOR, n. 115, 27/11/1817).

Tal como se expresaba, la instrucción no debía limitarse a instruir, sino a despertar en el corazón sentimientos útiles, elevados, patrióticos por lo cual se estimaba que, "lo más adecuado era introducir el método Bell y Lancaster”, un método que parecía “sencillo y ventajoso" (EL CENSOR, n. 82, 9/4/1817). De todos modos, esa renovación

\footnotetext{
${ }^{3}$ Cabe señalar que cuando transcribimos las fuentes de la época (tanto las editas como las inéditas), para no confundir a los lectores, se corrigieron los giros idiomáticos de la época e incluso los errores ortográficos.
} 
no encontró eco favorable entre los maestros. La propia prensa reflejaba las supuestas resistencias frente aquella novedad, comentando:

Esto sucede en Buenos Aires con el método de Lancaster: los maestros sostienen su antiguo método, y sin atender razones se oponen a la novedad sea la que fuera, por no tener el trabajo de aprender para enseñar con más fruto [...] para esta su resistencia alegan un pretexto muy especioso cual es el de la religión.

[...] voy a demostrarlo, que su miedo es infundado y su celo no está regulado por la prudencia, ni por la sabiduría, sin que antes bien es un efecto de ignorancia, extremoso en la materia. [...]

El hereje quacaro (sic) Lancaster expresamente dice que él no es el inventor [...] él sabía que su método era invención de los católicos, pero esa era una circunstancia muy accidental para el luego que se convenció de que el método era bueno [...]. (LA MATRONA COMENTADORA DE LOS CUATRO PERIODISTAS, 1821, s/f)

Las innovaciones en las escuelas elementales para varones (tanto de la ciudad como de la zona rural), fueron pocas salvo la enseñanza rudimentaria de los principios cívicos o lo que, solían también llamar catolicismo cívico. ${ }^{4}$ En la información sobre

\footnotetext{
${ }^{4}$ En otra publicación sobre los exámenes advertimos que, una de las materias se la designaba como "Doctrina y urbanidad cristiana". Los contenidos eran: los fundamentos y misterios de nuestra católica religión: conocimientos de los derechos de del hombre: obligación y modo de conservarlos en la sociedad, fundados todos en los principios de historia sagrada. Ver: Gaceta de Buenos Aires, Nº11, 15/3/1817. Este periódico fue creado por el secretario de la $1^{\circ}$ Junta Mariano Moreno quien editó su primer número el 7 de junio de 1810 y circuló hasta 1820. Salía 2 veces por semana, por lo general lunes y jueves. Contenido en general: circulares de la Junta Provisional de Buenos Aires, comunicaciones con España y con otros Cabildos.
}

los exámenes públicos de los alumnos de las escuelas gratuitas se señalaba que las asignaturas que se evaluaban eran "[...] los elementos de nuestra religión, caligrafía o arte de escribir; principios de la sociedad civil, gramática y ortografía castellana, y aritmética” (EL CENSOR, n. 32, 4/4/1816).

Ese clima de opinión favorables a la instrucción se hizo extensivo a algunos de los referentes de las comunidades como las de Ensenada que, dadas sus condiciones de vida socioeconómicas, pueden ser consideradas en aquellos tiempos como escuelas rurales. $\mathrm{Al}$ respecto, nos encontramos con una carta dirigida al Cabildo donde se dice:

El Teniente Alcalde y vecinos del pueblo de Ensenada que abajo suscribimos ante VE con el más alto respeto por este medio nos presentamos y decimos: que ha llegado a nuestra noticia la de haber dotado la ilustrada generosidad de V.E. varias escuelas destinadas a la enseñanza de los niños, que por la pobreza de sus padres carecen de este auxilio ya que distantes de la capital, no pueden acudir a su seno para recibir la educación a cuya influencia desearán en lo sucesivo sus particulares adelantamientos y el citado sus progresos y su más sólida lucha. [...] Llega a lo sumo el dolor con que miramos a nuestros tiernos hijos y vegetar en el embrutecimiento más vergonzoso sin que esté en los recursos de nuestra miseria el proporcionarles otras ventajas. Volver los ojos hacia atrás y nos irrita la memoria del plan premeditado que habían forjado los déspotas de conservar a los oprimidos americanos en la obscuridad y en el abatimiento una nueva generación. [...]" (ARCHIVO GENERAL DE LA NACIÓN: SALA IX-19-6-5, EN ADELANTE: AGN).

Fueron relativamente continuos los pedidos dirigidos al Cabildo para que se contemplara la posibilidad de establecer 
escuelas en aquellos pueblos "desolados e infelices”, tal como se los presentaba. Aquellas primeras escuelas que se financiaban con fondos de venta de ganado en corrales públicos, tuvieron acuciantes dificultades cotidianas, una de ellas fue encontrar preceptores capacitados para llevar adelante la tarea. Siguiendo con el caso citado de Ensenada, mientras se informaba al Cabildo que a la escuela podrían asistir "unos 49 alumnos y otros tantos de las estancias con lo cual serían según esos datos unos noventa”, el cura del pueblo comentó:

En todo este Pueblo ni en la Campaña de su jurisdicción se encuentra un sujeto aparente para el desempeño de Preceptor. A mí no me sería gravoso en servicio del Público contraerme a una ocupación tan beneficiosa para estos infelices niños para cuyo amor me seria gustosa esta tarea, pero como para el adelantamiento es necesaria una contracción diaria, en cumplimiento de mi ministerio me vería a dejarlos muchos días sin educación, para atender a las confesiones a los que soy llamado con frecuencia de la campaña, para lo que podrá V.E. nombrar a cualquier sujeto de los muchos que habrá de su satisfacción. (AGN: Sala IX-19-6-5)

El mismo cura de la comunidad señaló el tipo de instrucción que deberían recibir aquellos niños, acordes a los tiempos políticos de la revolución y la lucha por la independencia que promovían la formación de los nuevos ciudadanos. Así sostenía que,

\footnotetext{
[...] Los rudimentos políticos-cristianos en que deben ser empapados los jóvenes en sus tiernos años por el arbitrio de los establecimientos de escuelas públicas, tienen por principio desterrar aquellas tristes preocupaciones y vergonzosos abusos con que se procura hacer servir a la servidumbre previniendo oportunamente a la juventud para el estudio de los derechos
}

del hombre y de los del orden social [...] (AGN: Sala IX-19-6-5).

Por la misma prensa nos informamos que, finalmente, tras una serie de inconvenientes para designarlo como preceptor fue el mismo cura quien se hizo cargo de la enseñanza de la escuela en oportunidad de convocar los exámenes de los alumnos. (EL CENSOR, n. 150, 1/8/1818). ${ }^{5}$

Tal como se suponía, ese tipo de enseñanza rescataría a los rústicos de esas comunidades. Pero para ello era necesario que toda la tarea educadora fuera inseparable del conocimiento del dogma. La misión que le ocupaba a aquella escuela era la de erradicar ese cuadro de ignorancia “[...] origen de los más vergonzosos vicios de Padres a Hijos que hasta hoy se ha observado en los habitantes de la campaña” (AGN: Sala IX-19-6-5).

Con el paso del tiempo, y la experiencia de la propia práctica, quedó en evidencia que las dificultades eran muchas no solo para establecer una escuela sino también, para darle regularidad en su funcionamiento. Esas dificultades en gran medida tenían que ver con la falta de fondos por parte del erario público. El financiamiento para la guerra por la independencia primero y por los enfrentamientos internos de la guerra civil llevó el mayor esfuerzo económico de las autoridades. La insuficiencia de fondos, la falta de instalaciones adecuadas, de útiles y

\footnotetext{
${ }^{5}$ Días después se publica otra nota donde se informan de los premios que había otorgado el Cabildo a los que se destacaron en los exámenes: El Exmo. Cabildo ha premiado con dos medallas de plata y una de oro DD J. Marcelino Arroyo, Juan de Dios Dubal, y Pedro Pablo Castillo, alumnos de la escuela de primeras letras de la Ensenada, que es la primera de las del campo que ha presentado exámenes [...] El método de enseñanza ha sido aprender el silabario y la formación de caracteres, y a un mismo tiempo seguir escribiendo y leyendo. El preceptor es Fr. Rufino Roigt. (El Nº160, 10/10/1818. Exámenes en Ensenada.
} 
de libros, la escasez de recursos de los padres para costear la instrucción de sus hijos a las que, se sumaba la ausencia de preceptores.

En gran medida, estas dificultades tenían que ver con la labilidad de la presencia estatal. La primera década del gobierno de la Independencia había dejado como saldo un escenario político marcado por la guerra facciosa entre los centralistas -luego denominados unitarios- y los federales. Cuando en 1820 cayó el gobierno nacional, la ciudad de Buenos Aires y su campaña quedan bajo el gobierno el Partido del Orden. Por aquel tiempo se funda la Universidad de Buenos Aires en 1821, institución que tendría a su cargo el gobierno las escuelas primarias de la ciudad y la campaña buscando dar forma a un sistema general de educación en el que se adoptara el método lancasteriano. Asimismo se creó el cargo de Director de Escuelas y se cambiaron en la campaña las Juntas Protectoras por las Juntas Inspectoras conformadas por el Juez de Paz y dos “vecinos respetables" del lugar. Un detalle significativo es que, se buscó alejar de esa función a los curas párrocos en una evidente señal de la impronta liberal del momento. Sin embargo, los registros documentales dan cuenta de que las autoridades y vecinos locales continuaron acudiendo a los religiosos por su llegada a la comunidad.

Otra iniciativa de aquellos años fue la sanción de un nuevo reglamento de “Gobierno y Dirección del Colegio Rural” que data del 10 de octubre de $1825 .^{6}$ En el mismo se establecía que el colegio tendría su Director nombrado por el Gobierno Superior de la Provincia el cual recibiría en concepto de remuneración 500 pesos

\footnotetext{
${ }^{6}$ Hubo otros reglamentos en años anteriores pero nos detenemos en este porque se procuró avanzar en la redacción de una normativa escolar mucho más abarcativa que contemplara a la vida escolar en su totalidad. Esta cuestión se ha trabajado en: (LIONETTI, 2010)
}

anuales de sueldo. Entre sus funciones debía remitir al Prefecto de primeras letras cada seis meses las cuentas documentadas de su administración, las cuales se pasarán después al Rector de la Universidad para que las presentara al Ministro de Gobierno para su examen y aprobación. Entre otras cuestiones que debía registrar se le exigía que asentara en un libro los nombres de todos los alumnos, la fecha de su entrada y salida, anotando los que se distinguían por su conducta, aplicación y progresos, así como aquellos que se destacaban por su indocilidad o abandono para que sirviera de registro para los alumnos por si perdían sus certificados. Además del cuidado y administración del establecimiento, tenía el cargo de Preceptor de primeras letras y enseñaría no sólo a los Alumnos Colegiales, sino también a los del Pueblo y distrito de la Parroquia y para ello recibiría sobre su sueldo una compensación de cien pesos más que le pagaría el Gobierno. Debía utilizar el método de enseñanza mutuo. Destinaría una vivienda cómoda para los niños que concurren a la enseñanza y no sean alumnos del Colegio y se auxiliaría con los cuartos interiores. Debía dar a cada uno de sus Alumnos Colegiales en la Huerta del Colegio una fracción de terreno para que lo cuidara y lo cultivara con algunas plantas, hortalizas o pequeña sementera que cultivara para sí mismo. Para esta dedicación se señalarían todos los días al menos media hora de tiempo que se les dejara para recreo y descanso y una hora los días de Fiesta y Jueves. Se le recomendaba muy especialmente al Director la educación moral y religiosa de sus alumnos y haciéndoles asistir a Misa los días festivos. Debería esforzarse para que en el período de dos años el Alumno Colegial quedara medianamente instruido en leer, escribir y contar.

En otro apartado se hacía referencia a la admisión de los Alumnos pensionistas 
y de los llamados Alumnos de gracia. Los primeros no tendrían número determinado $\mathrm{y}$, en cuanto a los segundos, no superarían los veinte. Los Padres o Tutores de los alumnos pensionistas deberían pagar seis pesos al Comisario de Policía quien remitiría a su Jefe para que lo enviase a la Tesorería General. Los que eran alumnos de gracia no contribuirían ninguna suma de dinero y recibirían el mismo alimento y asistencia que los pensionistas. Los alumnos serían admitidos a partir de los siete años y hasta los quince debiendo comprometerse a aprender las primeras letras y a ser dóciles y obedientes a sus superiores.

Con una clara intención de dar una organización a la actividad en la escuela se preveía una rigurosa distribución del tiempo. La actividad comenzaría al amanecer despertando a los alumnos pensionados con el ruido de un instrumento que se tocara en la puerta del aposento. Después de vestirse, se lavarían y peinarían "con la decencia debida para ir a la capilla y hacer su deprecación al Supremo Creador del Universo y Padre de las luces”. Para esa preparación se les concedería tan solo media hora. Concluida la deprecación volverían a sus aposentos y de allí a la sala de enseñanza. Las clases desde fines de Noviembre a fin de Marzo comenzarían a las seis y media de la mañana, y desde Abril hasta fin de Octubre a las ocho y media. Se les enseñaría la Gramática Castellana, a leer, escribir y contar a través del método de mutua enseñanza. A la hora de las doce concluirían los ejercicios e irían a comer todos juntos presididos por el Vicedirector o el Director. Concluida la mesa se retirarían a sus Aposentos hasta las dos de la tarde para regresar a sus tareas hasta la cuatro tres cuarto desde $1^{\circ}$ de Abril hasta el mes de Agosto y hasta la seis desde $1^{\circ}$ de Setiembre hasta fin de Marzo. El tiempo sobrante por las tardes les serviría para el recreo en el terreno que a cada uno se le hubiera designado en la huerta para cultivarlo. Por la noche tendrían también tarea, pero en las noches cortas solos sería de una hora después de obscurecer y, en tiempo de noches largas, de hora y media. Una vez que concluyeran la tarea de la noche que no pasaría de las ocho y media irían a cenar. Al tiempo de comer y cenar se les leería algún tratado de agricultura o ganadería alternando con otros de buena crianza o educación. Los Alumnos deberían servirse a sí mismos y el Director debería atender que "los alumnos aprendieran todos los usos y prácticas de las que, se entendían tenía necesidad el hombre especialmente en el campo donde no era tan fácil proporcionarse el servicio de criados como en las ciudades” (AGN: Sala X 6-1-2)

Más allá de la recuperación de ese reglamento no se han encontrado indicios de su cumplimiento efectivo en las escuelas rurales. A pesar de los esfuerzos y relativos avances, era muy dificultoso para las autoridades hacer efectiva esas prescriptivas ante una referencia Por esa razón, las propias comunidades -a través de sus vecinos notables, los curas párrocos y los jueces de paz- tenían un margen de acción y de autonomía para ocuparse de los asuntos públicos. Y la enseñanza elemental no dejaba de ser rudimentaria y poco efectiva tanto para los propósitos que se habían fijado las autoridades como para los intereses de los propios vecinos.

A mediados de la década de los treinta, el gobierno en la provincia de Buenos Aires de Juan Manuel de Rosas dejó su impronta y una discontinuidad en materia de educación. $\mathrm{Su}$ primer foco de atención estuvo focalizado en la enseñanza particular que se había mantenido a lo largo de estos años con regularidad y sin mayores exigencias y controles por parte de las autoridades públicas de turno. Así se determinó que, en adelante, conforme a la moral de la Iglesia Católica Apostólica Romana, deberían contar con la 
autorización del Inspector General para su funcionamiento dentro del territorio de la provincia previa "justificaciones necesarias sobre la moralidad, religión y suficiencia” (AGN: Sala X-17-6-3).

Nuevamente se dejó como única fuente de financiamiento para las escuelas de la campaña los ingresos obtenidos de los corrales de abasto. Además, se decretó que no se debía exigir a los padres indigentes que sus hijos cumplieran con la instrucción escolar. Los fondos públicos se destinaron principalmente al mantenimiento de los gastos militares -producto de la urgencia que marcaba el estado de guerra que se vivió durante el régimen rosista- y para el clero que debía difundir el sermón patrióticofederal. Esa restricción de fondos llevó a que se cerrara la Casa de Expósitos y se suprimieran el pago de sueldos a maestros y todo tipo de gastos de escuelas (Recopilación de las Leyes y Decretos: 1836.)

La suerte de las escuelas de la campaña -incluso las escuelas de niñas que estaban bajo la gestión de las Damas de la Sociedad de Beneficencia- quedó librada a los esfuerzos de los pobladores de la campaña. ${ }^{7}$ Además, se otorgó el contralor de las escuelas y de su personal docente al Jefe de Policía, reduciendo claramente la injerencia del Inspector de Escuelas.

Después de la derrota en Caseros de Rosas en 1852 parecía que, en materia de instrucción, quedaba todo por hacer. Debía retomarse el rumbo que se había

\footnotetext{
${ }^{7}$ En este trabajo nos hemos ocupado de las escuelas elementales para varones (donde podían llegar a concurrir también niñas), pero cabe señalar que, a partir del año 1820 con las mencionadas reformas del Ministro Rivadavia, se dispuso que las escuelas públicas de niñas fueran administradas por la Sociedad de las Damas de la Beneficencia, que también se hizo cargo del Colegio de Huérfanos anteriormente a cargo de la extinguida Hermandad de Caridad. Esta cuestión ha sido trabajada en: (LIONETTI, p. 2010)
}

marcado durante los años veinte, eso fue lo que llevó a una búsqueda de centralización administrativa con la creación del Departamento de Escuelas y el posterior nombramiento de Sarmiento como Director; esos dos hechos marcarían un punto de inflexión que presenta un escenario político diferente en tanto se persiguió como meta la de finalmente hacer efectiva la construcción de un orden estatal.

\section{Las prácticas escolares en el corazón de la campaña}

La inestabilidad política, la lábil presencia de las autoridades estatales y el ensayo y error de una serie de medidas, sin lugar a dudas, marcó la discontinuidad de aquel objetivo alfabetizador que se habían fijado desde el mismo momento que se buscó cimentar un nuevo orden. Pero también, los evidentes límites en sus logros de esa enseñanza elemental mucho tenía que ver con las distancias entre lo que se prescribía de esa formación y la realidad social con la que se encontraba aquella escuela que pretendía civilizar al rústico escenario de la campaña.

La crisis de legitimidad que sigue a la caída del orden colonial no encuentra solución. Los gobiernos se suceden unos a otros y las amenazas a la posibilidad de construir un sistema político estable $\mathrm{y}$ ordenado, en vez de amainar, se incrementó progresivamente (Gelman: 1997, 36). La fragilidad de ese estado habría generado que el alcance de la gestión de gobierno fuera limitado ante la emergencia de lo social. A menudo encontraron resistencias y debieron negociar e incluso mediar entre funcionarios de segundo orden y los referentes de las propias comunidades para alcanzar cierto 
consenso. Esto precisamente se advierte claramente cuando nos aproximamos a la cuestión educativa en aquel contexto.

Un caso que ilustra en ese sentido, durante el año 1824 cuando desde el gobierno de Buenos Aires -tal como se explicó- se impulsó una serie de medidas de gobierno en materia educativa. Exactamente en la comunidad de Morón en el año 1824, los registros documentales nos permiten reconstruir un conflicto entre la Junta Celadora (conformada por vecinos notables) y el Preceptor nombrado por las autoridades. La conflictiva relación del Preceptor con aquellos vecinos se hizo evidente cuando los miembros de la Junta le exigen que presentara las instrucciones que tenía respecto a la utilización del sistema de Lancaster. Con cierta sorna y tono altanero el Preceptor envió una nota de respuesta donde les dice que

[...] desconoce el llamado sistema Lalcaster y que por eso no tenía esas instrucciones pero que si conocía las del Sr. Bell y el Señor Lancaster y si querían proveerse de un ejemplar se los acercaría puesto que el Superior Gobierno las tiene puesta a venia pública en la Biblioteca de la Universidad por el precio de un peso.

La respuesta de la Junta no se hizo esperar. Se le encarga “[...] más moderación en su modo de expresarse”. El intercambio continúa entre el Preceptor que reconoce como única autoridad a la Superioridad y la Junta que vuelve sobre el informe que debe acerca de su trabajo con el método de enseñanza. El conflicto llega hasta la autoridad responsable de las escuelas de primeras letras, el Rector de la Universidad de Buenos Aires. Precisamente el Rector, Antonio Sáenz, al informar al Ministro de Gobierno, Manuel García, comenta entre otros términos:
[...] El Gobierno tiene y recibe continuadas pruebas de que así como no me suele abandonar la prudencia tampoco me domina la imbecilidad o la irresolución para hacer frente a los que estando bajo mi inspección faltan a sus deberes o los prostituyen [...]. Mas como siempre ha sido la primera regla de mis procedimientos dar ejemplos de subordinación y respeto al Gobierno en la Universidad he llamado al Preceptor y le he vuelto la increpación .[...] Yo no he querido molestar a la superioridad ni distraer su atención con un asunto que estaba terminado.[...] Paso al Cura de Morón que se había empeñado en tratar al Preceptor como si fuera su Sacristán y en llevarse a los Niños de la Escuela a sus Misas cantadas para que se las sirviesen con prejuicio de la enseñanza [...]. Comenzó de repente a titularse Presidente de la Junta Celadora cuando en Morón nunca se ha establecido tal Junta y tan solo por mi parte que fui a la visita de Escuelas le hice la prevención de palabra para que él y el Juez de Paz estuvbiesen a la mira de la conducta de los Preceptores y me avisasen si faltasen a sus obligaciones. Este es el hombre quien de improviso veo titulase nada más y nada menos que en un Presidente y abusando del cambio de Juez de Paz se levanta con la autoridad de intimar ordenes al Preceptor de la Escuela y quieren obrar con independencia mía. El convoco al vecindario, le hizo elegir con otros para la Junta Celadora y me han pasado oficios haciéndome requerimientos tan groseros, tan desvergonzados y atrevidos [...]. Todo me parece que queda remediado con que el Preceptor se arregle con lo que tiene mandado y el Cura no tome parte en la dirección de la Escuela, pues que para el nuevo reglamento la Junta Inspectora solo se deba componer del Juez de Paz y dos vecinos. (AGN: Sala X 6-1-2).

La Junta responde que fue impuesta por los Padres de varios niños y que el Maestro, 
infligiendo el mandato de Gobierno que prohíbe todo castigo aflictivo e ignominioso, traspasa las disposiciones,

[...] estropeando las manos de los niños azotándolos con disciplina (aunque sobre las ropas) pero de un modo torpe, poniéndolos en el patio de la Escuela a la expectación de los que pasan por la plaza y autorizando a los demás niños a que hagan toda especie a befa a los que han sufrido aquel castigo. La Junta cree [...] que no es este el camino, ni el modo de conducir a los hombres por la senda del honor. [...] lejos de estimular en los niños las pasiones nobles [...] solo haga que pierdan el pudor y se formen entre ellos odios y enemistades [...]. (AGN: Sala X 6-1-2)

Llegan al punto máximo de presionar al Rector informando que cesarían de sus funciones si el Preceptor no se disculpaba. La respuesta del Rector fue contundente al sostener que los más perjudicados eran los vecinos "[...] porque siendo bastante difícil encontrar Maestros de buenas cualidades que quieran establecer en el campo, lo será mucho más que hasta se sepa que el Preceptor es molestado por el Juez y el Cura Párroco” (AGN: Sala X 5-1-2). La máxima autoridad finalmente decide que el Rector de la Universidad aperciba seriamente al Maestro por su conducta irregular y falta de respeto a los miembros de la Junta Inspectora y que, en lo sucesivo, se aplique los castigos correspondientes si no utiliza el sistema de Lancaster. Resulta más que evidente que la decisión de la máxima autoridad educativa de aquel momento se cortó por el hilo más débil, ordenando se apercibiera al preceptor que había desafiado a la Junta desconociendo su autoridad y referenciándose en aquella autoridad central que lo había designado. Sin embargo, esa autoridad de gobierno no pudo desconocer el malestar de los referentes - entre ellos el cura y el juez de paz- de aquella comunidad.

Las denuncias de las Juntas contra los preceptores fueron reiteradas y, en gran medida mucho tenía que ver con la ausencia de un cuerpo capacitado de educadores pese a los esfuerzos de las autoridades por promover una mejor formación. Uno de esos tantos casos ocurrió con la junta inspectora de la escuela de primeras letras del Fortín de Navarro quien manifestó la urgente necesidad de destituir de su preceptoría a Don Ramon Grimard por

[...] ser notoriamente ebrio, abandonando, inepto y aun malversador de los útiles confiados a su administración a beneficio de los hijos de Padres destituidos de recursos (AGN: Sala X 6-1-2).

Según se aduce, su inmoralidad y faltas notables habrían escandalizado a los padres de familia.

Se continuaba aduciendo que, hasta el Teniente Cura al examinar la escuela habría encontrado al Preceptor caído por la embriaguez en presencia de los discípulos, razón por la que hizo llamar al Juez quien lo amonestó. Sin embargo, sus faltas se reiteraron incluso en una reunión en su casa con sus amigos, a quienes habría molestado a punto de "[...] que lo tomasen, lo pusiesen sobre la mesa, le bajasen los calzones y la pusiesen de manifiesto la vergüenza y su esposa abochornada de las cosas que su marido daba lugar hiciesen con él, le obligó a irse a la Capital [... ]” (AGN: Sala X-6-1-2)

A esas conflictivas situaciones se le sumaba, además de todas las dificultades propias de la falta de presupuesto, aquella que se generaban a la hora de conciliar el ritmo escolar con el ritmo de las actividades que los niños cumplían en el campo junto a sus padres. Además de los meses de 
verano y cosecha, durante el resto del año las actividades rutinarias ocasionaron inasistencias más o menos recurrentes a las clases. Estas ausencias impactaban tanto en la posibilidad de aprender por parte de los alumnos, como en el prestigio y la estabilidad de los maestros -a quienes se culpaba de tal ausentismo- (Biroco: 2001). Aquella era una situación que se extendió a lo largo del siglo XIX y que llevó a que los propios preceptores debieran ajustar ese tiempo escolar-ideado desde el mundo urbano-. Los dichos de uno de ellos resultan reveladores cuando informaba a las autoridades que:

[...] Entre los niños que concurren a estas Escuelas, muchos tienen que hacer hasta dos leguas, por lo cual les es imposible estar presente a las 10 en la Escuela. Esta misma razón de distancia es la que nos obliga a cerrar las aulas más temprano los sábados; pues muchos niños y niñas se retiran, en este día, a casa de sus padres, a veces distantes a más de cinco leguas del pueblo. Como muchos niños vienen a la Escuela llevándose el almuerzo, por no haber tenido tiempo suficiente para almorzar antes de [sic] venir, nos hemos visto en la obligación de dar recreo de una sola vez. De todo esto resulta que solo 28 horas funcionan las Escuelas en lugar de 33h. como les corresponde. Sin embargo solo se pierde 3 horas de enseñanza en las materias; pues hemos creído más prudente disminuir más bien las horas de recreo que no las de clases [...]. ( RECOPILACIÓN DE LEYES Y DECRETOS, 1835, p. 52)

\section{Conclusión}

En aquella cartografía social de la campaña bonaerense, que lejos estuvo de ser una sociedad rural siempre igual a sí misma, caracterizada por la monoproducción ganadera, el predominio del latifundio $\mathrm{y}$ la presencia del gaucho, sino más bien un espacio donde se advertía la existencia de pequeñas y medianas explotaciones agrarias familiares mediados del siglo XIX, se hizo presente la escuela elemental. Esa escuela, proyectada para extender la civilización a un mundo que parecía marcado por la barbarie de los rústicos y el salajismo de los malones indígenas, debió insertarse en las comunidades donde sus referentes locales participaron de aquella iniciativa en favor de la alfabetización.

Aquella apuesta por extender los beneficios de la instrucción pública fue compartida por las autoridades centrales y por los notables locales -laicos y religiosos-, sin embargo, más allá de ese acuerdo hubo puntos de tensión y conflictos. Ese margen de acción que tuvieron los vecinos de esas comunidades, con sus "costumbres en común”, frente a la presencia de un estado signado por sus debelidades e indefiniciones marcó las singularidades de aquellas escuelas de primeras letras.

Si los esfuerzos habían sido muchos para alfabetizar a los niños y niñas, el cuadro de situación mostraba a todas luces la insuficiencia de aquello que se había promovido. De allí en más, y producto de los cambios políticos que van dando mayor protagonismo al Estado provincial, el avance del poder público sobre la educación se hará más visible dejando un menor margen para la acción de los pobladores, que lejos estuvieron de poder promover sus propias escuelas para el campo. Ese debate entre un Estado que promueve una escuela para las zonas rurales y aquellos sujetos sociales de ese mundo rural que pugnan por una escuela para el campo es necesario estudiarlo en profundidad para el caso argentino, pero esto excede la delimitación temporal de este trabajo. Es una deuda que contraemos con los lectores y que se espera poder avanzar en ese sentido. 


\section{Referências}

BIROCCO, C. La infancia en Morón durante el régimen rosista. In: CONGRESO DE HISTORIA DE LOS PUEBLOS DE LA PROVINCIA DE BUENOS AIRES, 8, 2001. Anais... Luján 8, 9 y 10 de noviembre de 2001.

BUSTAMANTE VISMARA, J. Las escuelas de primeras letras en la campaña de Buenos Aires (1800-1860). La Plata: Asociación Amigos del Archivo Histórico, 2007.

FERRO, G. Barbarie y civilización: sangre, monstruos y vampiros durante el segundo gobierno de Rosas. Argentina: Ediciones Marea, 2008.

GARAVAGLIA, J. C. Ecosistemas y tecnología agraria: elementos para una historia social de los ecosistemas agrarios rioplatenses (1700-1830). Desarrollo Económico, Buenos Aires, v.28, n.112, 1989.

HALPERÍN DONGHI, T. Revolución y guerra: formación de una elite dirigente en la argentina criolla. Buenos Aires, Siglo XXI, 1972.

IRUROZQUI, M.; PERALTA, V. Elite y sociedad en la América Andina: de la república de ciudadanos a la república de gente decente 1825-1880. Historia de América Andina, Quito, Universidad Andina Simón Bolívar, v. 5, 2003, p. 93-140.

LIONETTI, L. La misión política de la escuela pública en Argentina: formar a los ciudadanos de la república (1870-1916). Buenos Aires: Miño y Dávila, 2007.

MANDRINI, R. Indios y fronteras en el área pampeana (Siglos XVI y XIX). Balance y perspectivas. Anuario IEHS, Tandil, n.7, 1992.
MAYO, C. Vivir en la frontera: la casa, la dieta, la pulpería, la escuela (1770-1870). Buenos Aires: Biblos, 2002.

MORENO, J. M. La infancia en el Río de la Plata: ciudad y campaña de Buenos Aires 1780-1860. Cuadernos de Historia Regional. Luján, Universidad Nacional de Luján, 2000, n.20-21, p. 32-55.

NARODOWSKI, M. La expansión del sistema lancasteriano: el caso de Buenos Aires. Anuario IEHS, n.9, Tandil, 1994.

NEWLAND, C. Buenos Aires no es pampa: la educación elemental porteña 1820-1860. Buenos Aires: Grupo Editor de Latinoamérica, 1992.

ORTELLI, S.; RATTO, S. Introducción: dossier poder, conflicto y redes sociales en la frontera pampeana, siglos XVIII-XIX. Trabajos y Comunicaciones (2. Época), n.32/33, p.73-81, 2006/2007.

PALACIO, J. M. La paz del trigo: cultura legal y sociedad local en el desarrollo agropecuario pampeano, 1890-1945. Buenos Aires: Edhasa, 2004.

QUIJADA, M. ¿Qué nación?: dinámicas y dicotomías de la nación en el imaginario hispanoamericano del siglo XIX. Cuadernos de Historia Latinoamericana, AHILA, Hamburgo, n. 2, 1993-1994.

LIONETTI, L. Las damas de la sociedad de beneficencia educan a las hijas de la campaña bonaerense (1852-1875). In: WERLE, F. La educación rural en América Latina siglo XIX y XX. Brasilia: Editorial Liber Libros, 2010.

Recebido em: 10/05/2012 Aceito em: 27/06/2012 